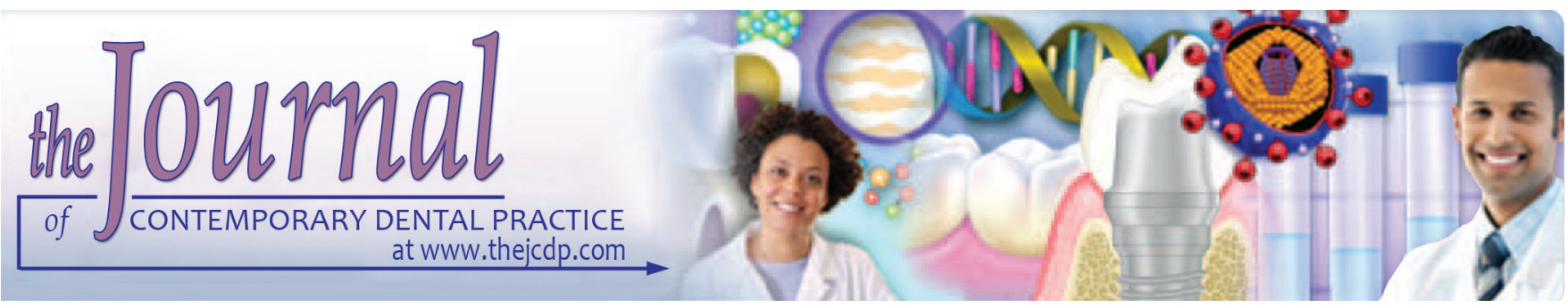

\title{
The Effect of Using a Modified Dentoalveolar Distractor on Canine Angulation following Rapid Canine Retraction: A Split-mouth Design Randomized Controlled Trial
}

${ }^{1}$ Khaled I Al-Ainawi, ${ }^{2}$ Yaser Al-Mdalal, ${ }^{3}$ Mohammad Y Hajeer

\begin{abstract}
Background and Objectives: New studies have been published and aimed to retract canines by means of distraction osteogenesis to reduce treatment time. Although a great care has been given to achieve a bodily movement of the canines, a significant amount of tipping of the canines has been observed. This trial aimed to assess the effect of applying a modified distractor on canine angulation.
\end{abstract}

Materials and methods: The sample of the study consisted of 14 canines in seven patients (16-25 years). After the osteotomy procedure, two distractors were applied (one distractor on each side). After 5 days of a latency period, the two distractors were activated at a rate of $1 \mathrm{~mm} /$ day.

Results: There was a significant difference between the two distractors regarding the time required to retract the canines $(p=0.008)$ and the observed change in canine angulation following retraction $(p=0.028)$. The change in the overjet and the mandibular plane angle was statistically insignificant. Eight out of 14 distracted canines reacted positively to the pulp vitality tester after 3 months of completion of distraction. There was no clinical sign of discoloration or pulpal pain in any canine.

Conclusion: Within the limits of this study, the modified distractor caused a bodily movement of the canine with a minimal tipping. Further research is required on a long-term basis on a larger group of patients to gain more insight on the observed changes.

Keywords: Dentoalveolar distraction, Distractor, Rapid canine retraction, Tooth vitality.

${ }^{1,2}$ Oral and Maxillofacial Surgery Department, University of Damascus Dental School, Damascus, Syria

${ }^{3}$ Orthodontic Department, University of Damascus Dental School, Damascus, Syria

Corresponding Author: Mohammad Y Hajeer, Associate Professor, Department of Orthodontics, University of Damascus Dental School, Damascus, Syria, Phone: +963940404840 e-mail: myhajeer@gmail.com
How to cite this article: The Effect of Using a Modified Dentoalveolar Distractor on Canine Angulation following Rapid Canine Retraction: A Split-mouth Design Randomized Controlled Trial. J Contemp Dent Pract 2016;17(1):49-57.

Source of support: Nil

Conflict of interest: None

\section{INTRODUCTION}

Orthodontic tooth movement is a process that combines both pathologic and physiologic responses to externally applied forces. ${ }^{1}$ One of the important phases in the extraction-based orthodontic treatment is canine retraction in two-step sliding techniques. ${ }^{2}$ Using conventional orthodontic traction techniques, biological tooth movement can be achieved at a limited rate, and the canine retraction phase often lasts 6 to 8 months. ${ }^{3}$

The long duration of orthodontic treatment is one of the major complaints of orthodontic patients. ${ }^{4}$ To date, several novel modalities have been reported to accelerate orthodontic tooth movement, including low-level laser therapy, pulsed electromagnetic fields, electrical currents, corticotomy, distraction osteogenesis and mechanical vibration. ${ }^{5}$ Distraction osteogenesis has been extensively applied to the craniofacial complex and is becoming a viable treatment option in the correction of craniofacial deformities. $^{6}$

Kisnisci et $\mathrm{al}^{7}$ introduced a new technique named dentoalveolar distraction (DAD), which has been shown to produce rapid tooth movement using the principles of distraction osteogenesis by means of a transportation of a bone disc to move a dentoalveolar segment. Distraction osteogenesis is a method of inducing new bone formation by applying mechanical stretching of the preexisting bone. ${ }^{8}$ This procedure has been shown to be well tolerated by patients. No anchorage loss, root resorption, dental 
ankylosis or loss of vitality was detected. ${ }^{7}$ Complications such as sinus exposure, delayed soft tissue closure and dehiscence have been said to be avoided with proper case selection and refined surgical procedure. ${ }^{9}$

The distal displacement of the canines was always accompanied with different degrees of distal tipping that ranged from 7.11 to $13.15^{\circ} .^{9-14}$ Therefore, the distal displacement of the canines was mainly a combination of tipping and translation.

In an attempt to achieve a bodily movement of the canines with distraction osteogenesis, a modified distractor was developed at the Department of Oral and Maxillofacial Surgery at University of Damascus Dental School and the preliminary tests showed good results regarding minimizing the tilting phenomenon of the conventional dentoalveolar distractor. ${ }^{15}$

The objectives of this randomized controlled trial (RCT) were to compare the modified distractor with the conventional one in terms of (1) dentoalveolar changes following canine retraction, (2) time required for retraction, (3) vitality of the retracted canines by this procedure.

\section{MATERIALS AND METHODS}

\section{Study Design and Setting}

This study is a randomized clinical trial with a splitmouth design conducted at the Departments of Oral and Maxillofacial Surgery and Orthodontics at University of Damascus Dental School between June 2014 and July 2015 and was funded by the University of Damascus Postgraduate Research Budget (92954206384DEN). This trial was registered in the ClinicalTrials.gov website (NCT02332421).

\section{Patients' Recruitment}

This study was approved by the local research ethics committee (UDDS-REC2418/2015/OMFS). A priori sample size calculation was performed using G-Power software (G-Power ${ }^{\odot}$ 3.1.7; Franz Faul, Universitat Kiel, Germany). Using paired-samples $t$ test with an alpha level of 0.05 , a power of $80 \%$, SD of canine angulation $=4.65^{\circ} 12$ and assuming that the smallest difference requiring detection in canine angulation was $5^{\circ}$, a sample of 10 patients was required.

The sampling frame was obtained by screening the records of patients who had visited the Department of Orthodontics of University of Damascus Dental School from June 2013 to September 2014. Forty-seven patients with a primary diagnosis of Class II division 1 malocclusion were recalled after reviewing their orthodontic records. Forty-three patients were diagnosed with an upper dentoalveolar protrusion after a detailed clinical examination. Twenty patients fulfilled the following inclusion criteria: a treatment plan of bilateral extraction of the first premolars followed by canine retraction, no endodontic treatment of the retracted canines, no severely abnormal positioning of the canines, no previous orthodontic or surgical treatment, no contraindication for performing a minor surgery and the presence of good oral hygiene. The trial was explained to the 20 candidates. Five patients declined participation, whereas 15 accepted the inclusion in this trial. According to our calculation of sample size, 10 patients were randomly selected. Each patient was asked to pick an opaque, sealed envelope from a container to allocate the modified distractor side. The container included five envelopes with the letter ' $R$ ', indicating the right side and five envelopes with the letter ' $\mathrm{L}$ ' for the left side. The surgical intervention was performed by the same principal researcher (K. A-A). Unfortunately, three patients were lost to follow-up because of their sudden migration outside the country due to the current crisis in Syria, so the final sample size was seven patients (i.e., 14 canines). Flow Chart 1 shows the CONSORT 2010 flow chart of this study.

\section{The Dentoalveolar Distractor}

A conventional hyrax screw was used as a distractor. The original dentoalveolar distractor consisted of two arms resting on the canine and first molar bands by cutting of the other two arms of the hyrax screw. The modified DAD had three arms, two resting on the canine and first molar bands and one was shortened and bent to rest on a bony point located mesially and apically to the canine dentoalveolar segment (Fig. 1).

\section{Surgical Intervention}

After administration of local anesthesia (buccal and palatal), a sulcular incision was made extending from the mesial interdental papilla of the canine to the distal interdental papilla of the first molar. In addition, a vertical releasing incision beginning mesial to the distal interdental papilla of the lateral incisor was made. A mucoperiosteal flap was elevated and the area around the canine and first premolar was exposed. An osteotomy line was marked around the root of the first premolar (Fig. 2), and after that, the first premolar was extracted with its buccal bone plate. The length of the canine was measured depending on the length of the first premolar. A reference point was formed $5 \mathrm{~mm}$ above the canine apex in the alveolar bone and an osteotomy line was made mesial to the canine so the buccal bone of the canine root was marked (Fig. 3). The palatal wall of the extraction socket 
Flow Chart 1: CONSORT2010 flow chart of patients' recruitment and follow-up

47 patients with a primary diagnosis of Class II division 1 malocclusion
were recalled after screening the orthodontic records of 760 patients

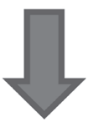

43 patients were diagnosed with an upper dentoalveolar protrusion after a detailed clinical examination

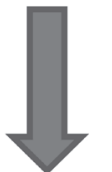

20 patients fulfilled the inclusion criteria
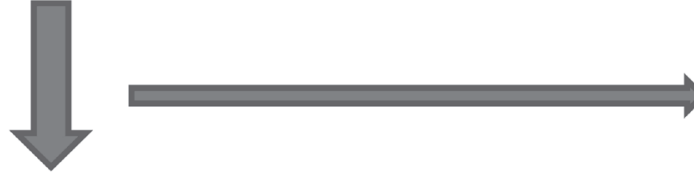

15 patients accepted the possible inclusion in this trial

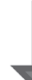

10 out of 15 patients were randomly selected and the sides of the distractors (original, modified) were randomly selected.

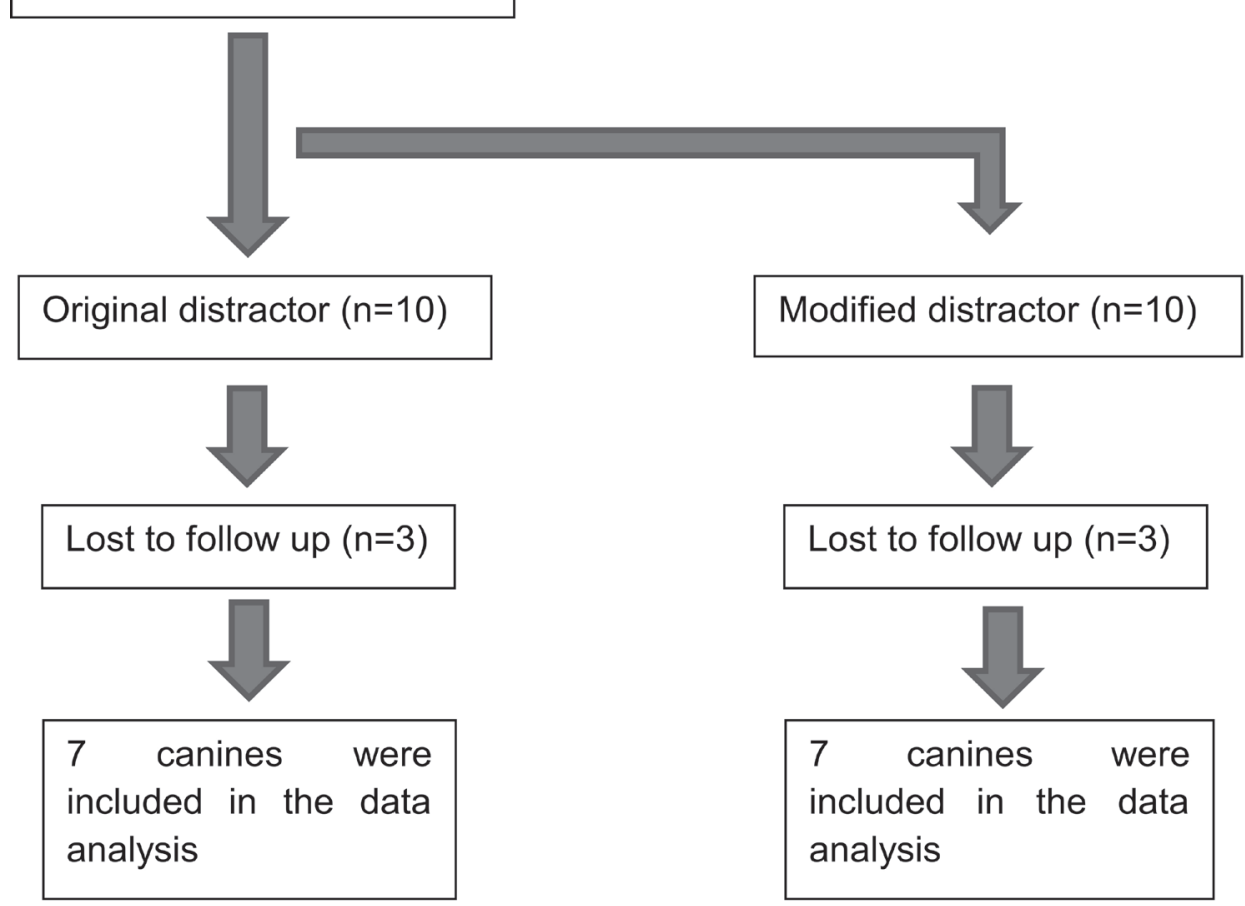

23 patients were excluded:

12 patients with poor oral hygiene

7 patients with abnormal positioning of the canines

3 patients with previous orthodontic treatment

1 patient with canine endodontic treatment

5 patients declined participation 


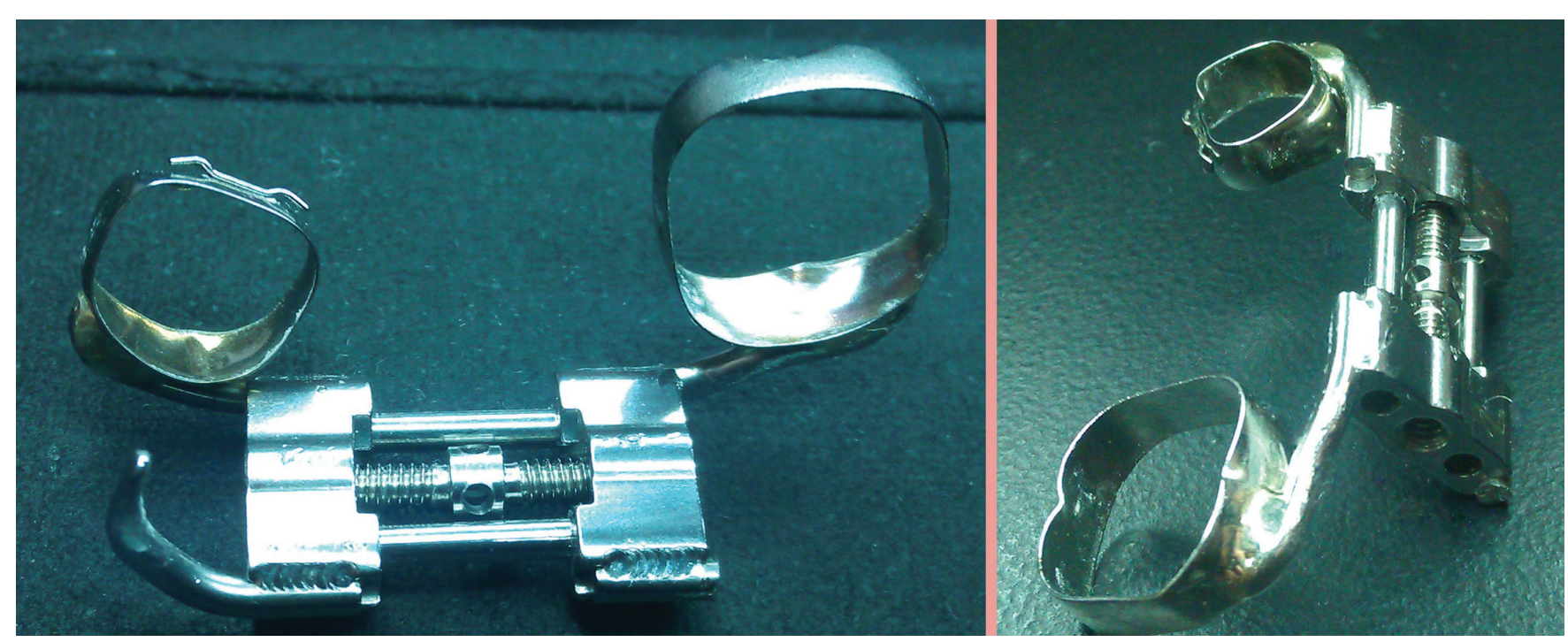

Fig. 1: The dentoalveolar distractor (original R, modified L)

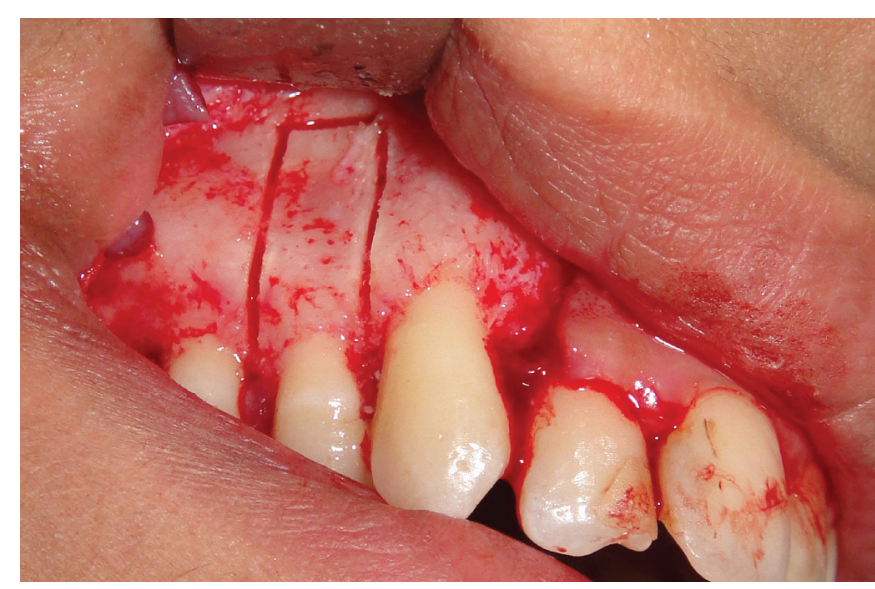

Fig. 2: An osteotomy line marked around the root of the first premolar

was ground and the depth of the extraction socket of the first premolar was increased with a round bur till it reached the reference point above the canine apex (Fig. 4). Fine osteotomes in appropriate sizes were used along the anterior aspect of the dentoalveolar segment that includes the canine to split the surrounding bone around its root

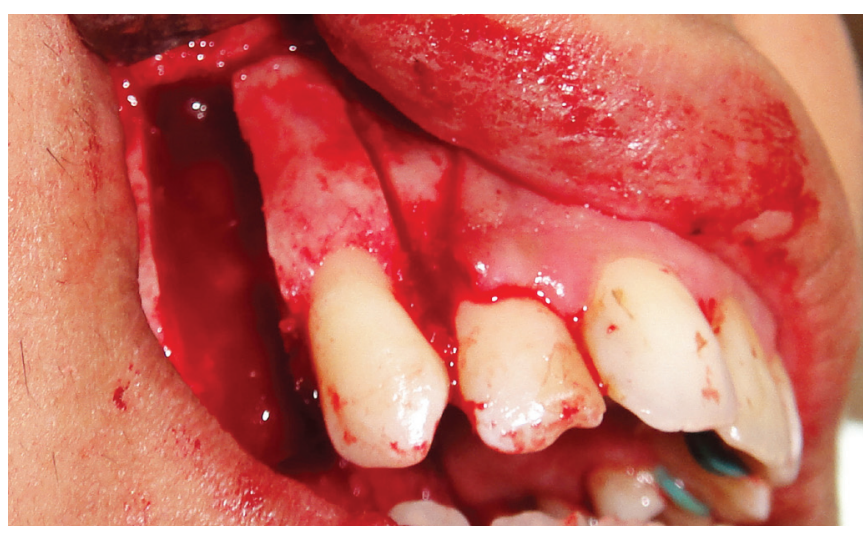

Fig. 4: Increasing the depth of the extraction socket

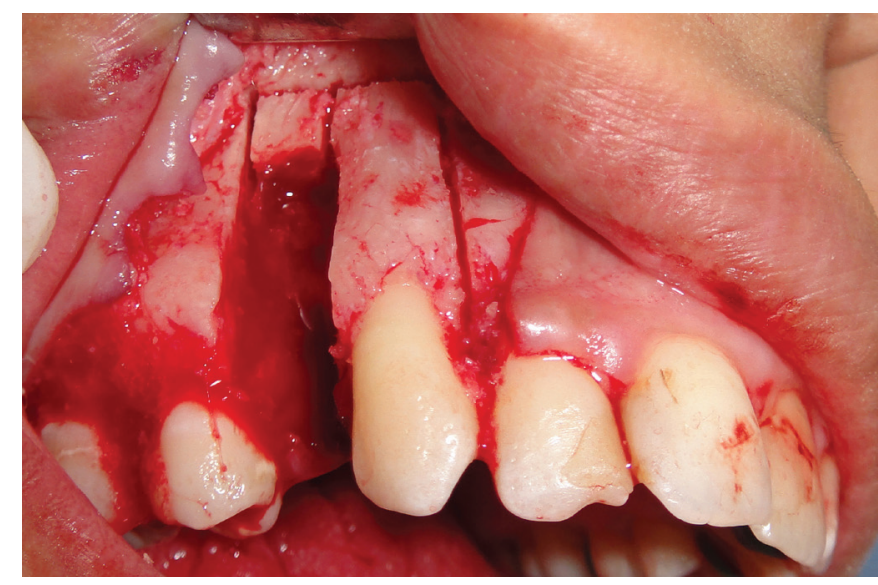

Fig. 3: The buccal bone of the canine root marked

off the lingual cortex and the neighboring teeth. Wound was closed with a single mucosal layer using sutures. After that, the traditional distractor was cemented with glass ionomer cement.

The same procedure was performed on the opposing side for the modified distractor. Before its cementing, the third arm was adapted to enter the osteotomy line at a mesial and apical point to the canine (Fig. 5). Then, the flap was repositioned and sutured. Patients were prescribed an intramuscular injection of Diclofenac Sodium after surgery, antibiotics and nonsteroidal antiinflammatory drugs for 5 days (Diclofenac Potassium $50 \mathrm{mg}$ ). After 5 days, sutures were removed (Fig. 6).

\section{Activation Protocol of the Retraction Distractor}

Distraction started within 5 days and the rate of distraction was $1 \mathrm{~mm}$ per day. The distractor was activated 0.5 $\mathrm{mm}$ twice a day. Distraction period was discontinued once the canine moved posteriorly into the desired 


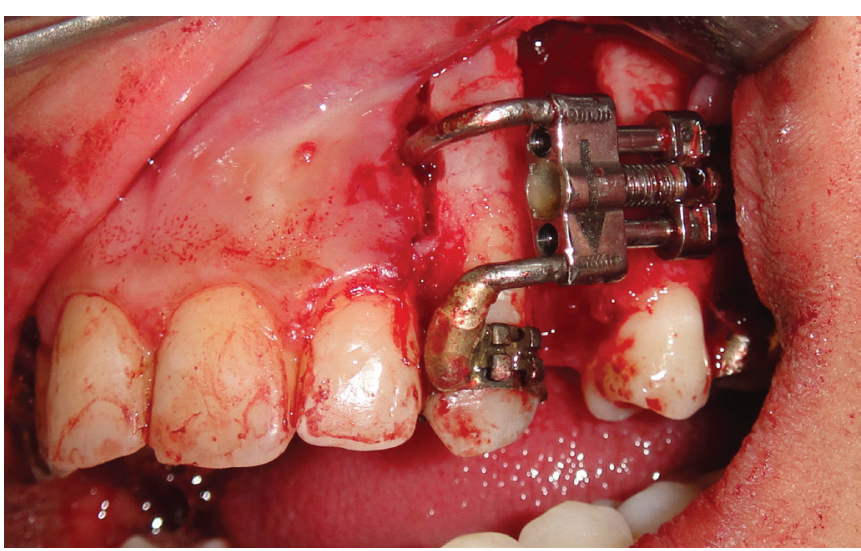

Fig. 5: Adapting of the third arm

position (i.e., Class I canine relationship with/without contact with the second premolar). Then, the distracted dentoalveolar segment with the distraction device was kept passive for 1 month as a consolidation period. Later on, the conventional orthodontic therapy was resumed by retracting the four upper incisors by one of the Orthodontic postgraduate students under the supervision of one of the coauthors (MYH).

\section{Cephalometric Assessment}

\section{Fabrication of the Canines' Markers}

A suitable band for the canine was selected (which had a bracket on it); then, a stainless steel wire was adapted, one side of it to be inserted into the bracket slot and the other one to extend apically parallel to the longitudinal axis of the canine. The end of the wire was twisted distally for the right canine and mesially for the left canine (Fig. 7).

Standardized lateral cephalometric radiographs were taken (with the canines' markers in place) at two assessment times: before (Fig. 8) and after the completion of distraction. Digitization, tracing and analysis of the blinded radiographs were performed by the first author (K. A-A) employing a special cephalometric program Viewbox ${ }^{\circledR}$ (Version 4.0.0.98; dHAL Software, Kifissia, Greece). The program created a horizontal plane (N-HL) that was constructed by a clockwise rotating of Sella-Nasion line (SN) $7^{\circ}$ around Nasion, and a line perpendicular to it through Sella was constructed (S_ vertical). Then, dental measurements (linear and angular) were performed (Table 1).

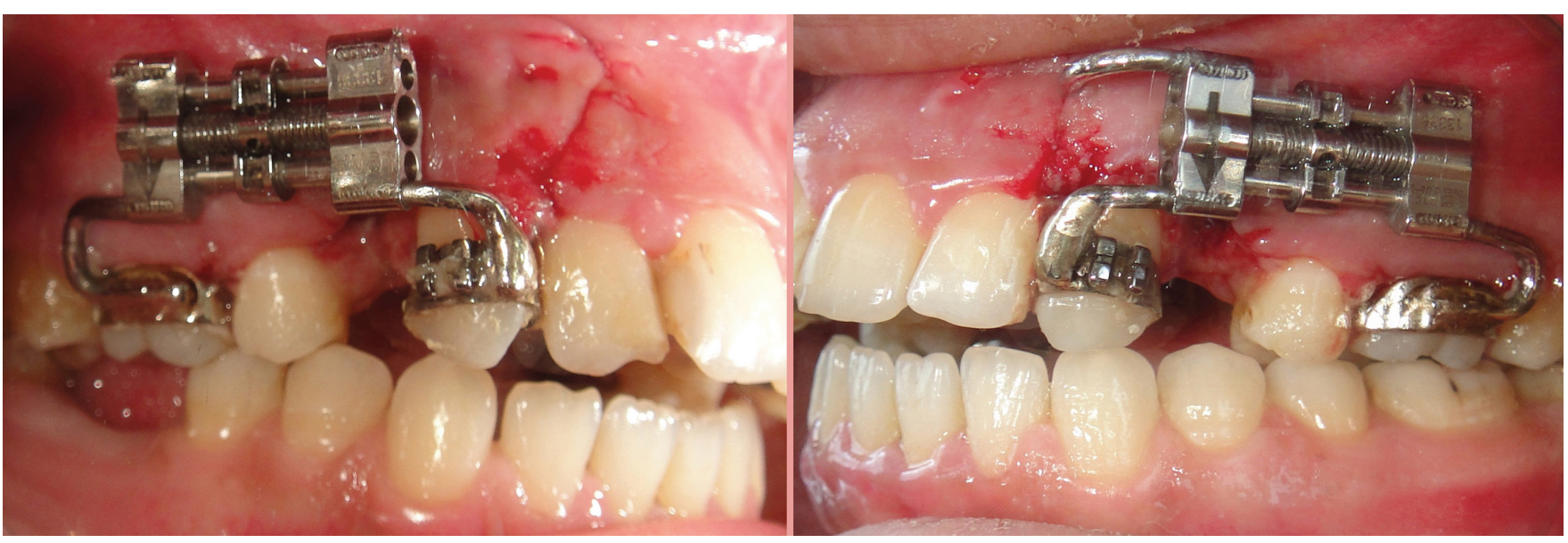

Fig. 6: Removing sutures after 5 days

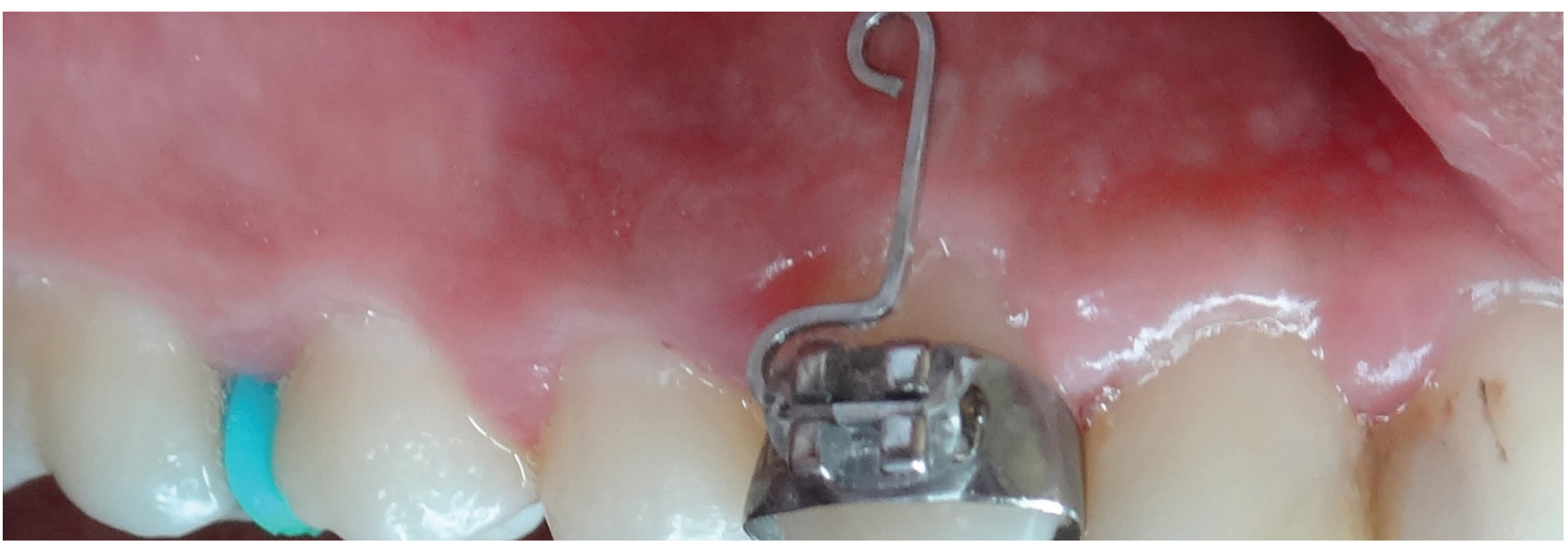

Fig. 7: The canine's marker on the right canine heading distally 


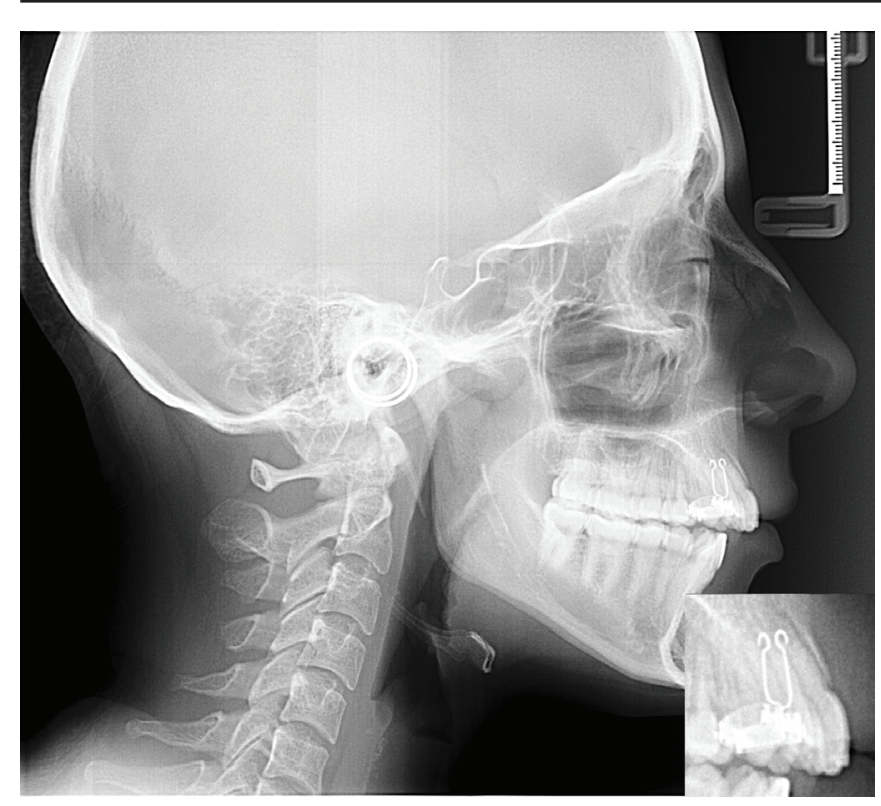

Fig. 8: A lateral cephalogram with the canines' markers in place

\section{Outcome Measures}

One variable was related to the required distraction time, whereas the other variables were measured on the cephalograms: (1) the amount of distal displacement, (2) the axial inclination of the distracted canines, (3) the maxillary incisors' inclination angle and (4) the mandibular-cranial base angle. Definitions of these measurements are given in Table 1. In addition, the vitality of the involved canines was evaluated using an electrical pulp tester. The cephalometric assessment was based on two cephalograms taken immediately before and after the distraction procedure, whereas the assessment of canine vitality was performed at the following assessment times: immediately predistraction, immediately post-distraction and after 3 months post-distraction.

\section{Statistical Analysis and Error of the Method}

Statistical analysis was conducted using Minitab ${ }^{\circledR} 17$ (USA, Pennsylvania State University). Paired-sample $t$ tests were employed to evaluate the intra- and intergroup changes before and after distraction. AndersonDarling normality tests were performed to check the distribution of data. The error of the measurement
Table 1: Definitions of the cephalometric outcome measures in this trial

\begin{tabular}{|c|c|c|}
\hline $\begin{array}{l}\text { Angular and } \\
\text { linear } \\
\text { measurements } \\
\end{array}$ & Outcomes & Definitions \\
\hline UC.SV $^{*}$ & $\begin{array}{l}\text { The horizontal } \\
\text { distance of the } \\
\text { canine }\end{array}$ & $\begin{array}{l}\text { The horizontal distance } \\
\text { between the upper canine's } \\
\text { marker and S_vertical (SV) } \\
\text { plane }\end{array}$ \\
\hline $\begin{array}{l}\text { UC.ANS- } \\
\text { PNS }^{\dagger}\end{array}$ & $\begin{array}{l}\text { Axial inclination } \\
\text { of the distracted } \\
\text { canine }\end{array}$ & $\begin{array}{l}\text { The angle between the upper } \\
\text { canine's marker and the } \\
\text { maxillary plane }\end{array}$ \\
\hline UI.SN ${ }^{\dagger}$ & $\begin{array}{l}\text { The maxillary } \\
\text { incisor } \\
\text { inclination angle }\end{array}$ & $\begin{array}{l}\text { The angle between the } \\
\text { anterior cranial base and the } \\
\text { upper incisor axis }\end{array}$ \\
\hline GoMe.SN $^{\dagger}$ & $\begin{array}{l}\text { The mandibular } \\
\text { plane angle }\end{array}$ & $\begin{array}{l}\text { The angle between the } \\
\text { anterior cranial base and the } \\
\text { mandibular plane }\end{array}$ \\
\hline
\end{tabular}

"Linear measurements (measured in $\mathrm{mm}$ ); ${ }^{\dagger}$ Angular measurements (measured in degrees)

method was calculated from double measurements of the seven cases. The measurement was repeated after a 4-week interval for the selected patients. The error of the method was considered low. No systematic error was detected using paired $t$ tests. The intraclass correlation coefficient confirmed the high reliability of measurements (Table 2).

\section{RESULTS}

The results regarding the duration of the retraction procedure, distal displacement and axial inclination of the canines are given in Table 3. There was a significant difference between the two groups regarding the distraction duration $(p<0.01)$. There was no statistically significant difference between the two distractors regarding the overall distal movement of the canines $(p=0.954)$. There was a significant change in canine angulation in the conventional distractor group $(\mathrm{p}<0.05)$. But the change in canine angulation in the modified distractor group was insignificant $(p=0.054)$. A statistically significant difference was observed between the two distractors regarding the axial inclination of the retracted canines $(\mathrm{p}<0.05)$.

The results regarding changes of incisor inclination and mandibular plane angle are given in Table 4 . There

Table 2: Reliability of the measurements taken and the error of the method

\begin{tabular}{|c|c|c|c|c|c|c|c|c|c|c|}
\hline Variables & $T 1-1^{*}$ & $T 1-2$ & $T 1-2-T 1-1$ & $P$-value $\neq$ & $I C C^{\S}$ & $T 2-1^{\dagger}$ & $T 2-2$ & $T 2-2-T 2-1$ & $p$-value & $I C C^{\S}$ \\
\hline UC.SV & 77.09 & 77.01 & -0.079 & 0.708 & 0.999 & 70.44 & 70.46 & 0.021 & 0.902 & 0.999 \\
\hline UC.ANS-PNS & 91.82 & 91.92 & 0.100 & 0.613 & 0.999 & 83.31 & 82.87 & -0.436 & 0.112 & 0.999 \\
\hline UI.SN & 97.21 & 96.09 & -1.129 & 0.172 & 0.992 & 96.56 & 95.57 & -0.986 & 0.093 & 0.995 \\
\hline GoMe.SN & 35.53 & 36.50 & 0.971 & 0.179 & 0.995 & 35.76 & 36.77 & 1.014 & 0.109 & 0.997 \\
\hline
\end{tabular}

T1-1 and T1-2 are first and second measurements of the first assessment time; ${ }^{\dagger} \mathrm{T} 2-1$ and $\mathrm{T} 2-2$ are first and second measurements of the second assessment time; ${ }^{\ddagger}$ Systematic error was assessed using paired $t$ tests. ${ }^{\S}$ Intraclass correlation coefficients for random error assessment; Variables' definitions are given in Table 1 
Table 3: Descriptive statistics of the evaluated variables and the results of significance tests of intra- and inter-group

\begin{tabular}{|c|c|c|c|c|c|c|c|c|c|}
\hline \multirow[b]{2}{*}{ Variables } & \multicolumn{4}{|c|}{ Conventional Distractor } & \multicolumn{4}{|c|}{ Modified Distractor } & \multirow{2}{*}{$\begin{array}{l}\text { Conventional } \\
\text { vs. Modified } \\
p \text {-value }\end{array}$} \\
\hline & Before* & After & Difference & $p$-value & Before* & After & Difference & $p$-value & \\
\hline UC.SV & $77.17(11.30)$ & $70.53(12.03)$ & $-6.643(2.212)$ & $<0.001$ & 77.01(11.72) & $70.34(11.90)$ & $-6.671(2.180)$ & $<0.001$ & 0.954 \\
\hline $\begin{array}{l}\text { UC.ANS- } \\
\text { PNS }\end{array}$ & $87.37(7.15)$ & 73.31(13.30) & $-14.06(12.32)$ & 0.023 & $96.27(11.38)$ & $93.30(11.88)$ & $-2.97(3.29)$ & 0.054 & 0.028 \\
\hline $\begin{array}{l}\text { Duration } \\
\text { of } \\
\text { Retraction }\end{array}$ & \multicolumn{4}{|c|}{8.714 days (2.563) } & \multicolumn{4}{|c|}{10.143 days $(2.545)$} & 0.008 \\
\hline
\end{tabular}

Test used: Paired t-tests; *Figures mentioned are mean values and standard deviations are given between brackets; Variables' definitions are given in Table 1

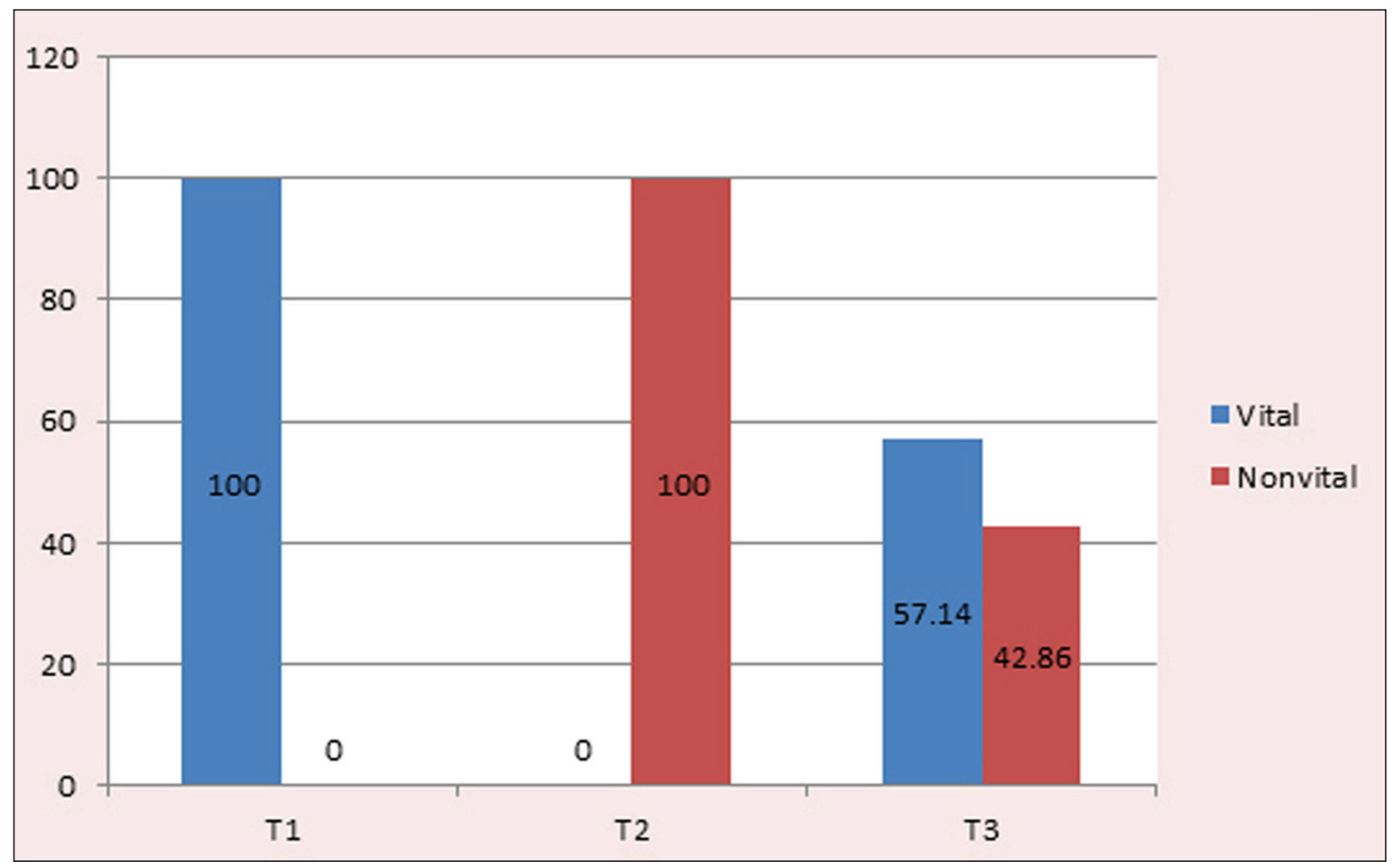

Graph 1: Vitality changes during assessment times

was no statistically significant difference regarding anterior incisor inclination following the completion of the distraction procedure $(p=0.458)$. There was no statistically significant difference also regarding the changes observed in the mandibular plane angle $(\mathrm{p}=0.517)$.

All the 14 canines in the study were vital before the distraction procedure. However, none of them reacted positively to the vitality test after completion of the

Table 4: Descriptive statistics of the evaluated variables and the results of significance tests of the observed changes

\begin{tabular}{lllll}
\hline & Before & After & Difference & $P$ - \\
Variable & Mean $\left(S D^{*}\right)$ & Mean (SD) & Mean (SD) & value \\
\hline UI.SN & $97.21(10.56)$ & $96.56(8.80)$ & $-0.657(2.192)$ & 0.458 \\
GoMe.SN & $35.53(12.24)$ & $35.76(12.34)$ & $0.229(0.879)$ & 0.517 \\
\hline
\end{tabular}

Test used: Paired t tests; *SD: Standard deviation; Variables' definitions are given in Table 1 distraction. In each group, four out of seven canines were vital at 3 months following the distraction completion (Graph 1).

\section{DISCUSSION}

Since the first suggestion of using distraction osteogenesis devices in rapid canine retraction by Iseri et $\mathrm{al}^{12}$ in 2001, the effect of this technique on canine angulation has been previously reported by many authors. And the distal displacement of the canines was mainly a combination of tipping and translation. . $^{8,15}$

The tipping of the canines occurs mainly as a result of the applied surgical technique and the accompanying relief of any bony interferences at the apical region of the tooth during dentoalveolar canine segment retraction. ${ }^{6,13,14}$ Another factor is related to the position and 
orientation of the distractor that should be ideally very close to the center of resistance of the canine. ${ }^{13,14}$

In the present study, clinically adequate retraction of the canines in the control group was achieved in 5 to 12 days, while it took 7 to 14 days in the modified distractor group. There was a statistically significant difference between the two distractors. This could be due to the application of two forces by the modified distractor vs one by the original distractor and this may have caused additional delay in canine retraction to the desired place. Kisnisci et $\mathrm{al}^{7}$ have reported a retraction duration of 8 to 12 days, whereas Sukurica et $\mathrm{al}^{10}$ reported 12 to 28 days Differences between these studies could be due to the type of the employed distractor as well as the design of the surgical intervention.

The original distractor caused a combination of tipping and translation movement, and the mean change in the axial inclination of the canine was $14.06^{\circ}$ (range: $\left.1.4^{\circ}-33.8^{\circ}\right)$, whereas the modified distractor caused a bodily movement with minimal amount of tipping with a mean of $3.03^{\circ}\left(-1\right.$ to $\left.7.5^{\circ}\right)$. The anterior two arms of the modified distractor applied two traction forces: the first one was apical and somewhat close to the center of resistance of the canine and the other one was coronal. And these two forces may have caused a bodily movement of the dentoalveolar segment. It should be noted that this is the first RCT that objectively evaluated the effect of changing the design of the distractor on canine angulation after DAD compared with the original model using a split-mouth study design.

The change in anterior incisor inclination following canine retraction ranged from $-3.5^{\circ}$ to $3.5^{\circ}$, which was statistically insignificant. Raj and John ${ }^{9}$ found that the decreased overjet was insignificant too $(0.2 \pm 0.4 \mathrm{~mm})$. Iseri et $\mathrm{al}^{12}$ showed a significant reduction of overjet, but their mean value of change was $0.34 \pm 0.44 \mathrm{~mm}$, which was clinically insignificant. They claimed that this movement was related to the spontaneous movement of the incisors into newly formed fibrous bone.

A statistically insignificant difference regarding the change in mandibular plane angle following distraction was observed between the two groups. While Iseri et $\mathrm{al}^{12}$ and Raj and John ${ }^{9}$ found that mandibular plane angle had increased during retraction, they related that to the insignificant amount of extrusion of the maxillary first molars. It seems to be the difference observed between the current study and previous reports could be attributed to the method of performing the surgical intervention. If the dentoalveolar segment was allowed to retract by distraction freely with less resistance from the surrounding structures, this may reduce the untoward effects on molars and a less extrusion of these teeth could be anticipated.
Six canines showed no response to the electrical pulp testing performed 3 months after completion of the distraction. There was neither clinical sign of discoloration nor pulpal pain in any of the distracted canines. The absence of vitality response of the six canines could be due to the short period of follow-up. Many authors mentioned that none of the teeth reacted negatively to the electrical vitality test 6 months after completion of distraction, ${ }^{7,8,13}$ while others reported that a number of canines did not respond to the electrical vitality test after 3 or 6 months of distraction completion with no clinical sign of discoloration or pulpal pain in any tooth. ${ }^{9,10}$ Many authors pointed out that the pulp-vitality test is not a reliable technique when performed during orthodontic tooth movement. ${ }^{8,9,12}$

The strength of the present research work is being the first RCT assessing the use of a modified distractor to avoid canine inclination during rapid canine retraction compared with the original distractor in a split-mouth design. However, several shortcomings should be avoided in future clinical trials, including (1) the need for longer follow-up periods to assess canine vitality after distraction; (2) the need for a larger group of patients to avoid statistical false-negative findings; and (3) the need for studying other important variables such as periodontal health of the distracted canines and the associated levels of pain and discomfort.

\section{CONCLUSION}

Distraction osteogenesis for rapid canine retraction is a promising technique. The canines can be fully retracted within 5 to 14 days. The modified distractor caused a bodily movement of the canine with a minimal tipping.

\section{REFERENCES}

1. Wise GE, King GJ. Mechanisms of tooth eruption and orthodontic tooth movement. J Dent Res 2008 May;87(5):414-434.

2. Al-Sibaie S, Hajeer MY. Assessment of changes following en-masse retraction with mini-implants anchorage compared to two-step retraction with conventional anchorage in patients with class II division 1 malocclusion: a randomized controlled trial. Eur J Orthod 2014 Jun;36(3):275-283.

3. Gurgan CA, Iseri H, Kisnisci R. Alterations in gingival dimensions following rapid canine retraction using dentoalveolar distraction osteogenesis. Eur J Orthod 2005 Aug;27(4):324-332.

4. Kurt G, Iseri H, Kisnisci R. Rapid tooth movement and orthodontic treatment using dentoalveolar distraction (DAD). Long-term (5 years) follow-up of a Class II case. Angle Orthod 2010 May;80(3):597-606.

5. Long H, Pyakurel U, Wang Y, Liao L, Zhou Y, Lai W. Interventions for accelerating orthodontic tooth movement: a systematic review. Angle Orthod 2013 Jan;83(1):164-171.

6. Nair A, Kumar JP, Venkataramana V, Yuvaraj A, Reddy VS, Kumar SK. Dento-alveolar distraction osteogenesis using rigid intra-oral tooth borne distraction device. J Int Oral Health 2014 Apr;6(2):106-113. 
7. Kisnisci RS, Iseri H, Tuz HH, Altug AT. Dentoalveolar distraction osteogenesis for rapid orthodontic canine retraction. J Oral Maxillofac Surg 2002 Apr;60(4):389-394.

8. Kumar N, Prashantha G, Raikar S, Ranganath K, Mathew S, Nambiar S. Dento-alveolar distraction osteogenesis for rapid orthodontic canine retraction. J Int Oral Health 2013 Dec;5(6):31-41.

9. Raj AB KM, John RR. Rapid canine retraction with dentoalveolar distraction osteogenesis: an in vivo study. J Ind Orthod Soc 2013 Jan;37(1):21-27.

10. Sukurica Y, Karaman A, Gurel HG, Dolanmaz D. Rapid canine distalization through segmental alveolar distraction osteogenesis. Angle Orthod 2007 Mar;77(2):226-236.

11. Deepak C, Kannan MS, Sukumar MR, Rajesekar L, Datta U. A new approach for evaluation of canine dento alveolar distraction using cone-beam computed tomography. J Pharm Bioallied Sci 2015 Apr;7(Suppl 1):S125-S130.
12. Iseri $\mathrm{H}$, Kisnisci $\mathrm{R}$, Bzizi N, Tuz H. Rapid canine retraction and orthodontic treatment with dentoalveolar distraction osteogenesis. Am J Orthod Dentofacial Orthop 2005 May; 127(5):533-541; quiz 625.

13. Kharkar VR, Kotrashetti SM. Transport dentoalveolar distraction osteogenesis-assisted rapid orthodontic canine retraction. Oral Surg Oral Med Oral Pathol Oral Radiol Endod 2010 May;109(5):687-693.

14. Acharya SP, Sahu S, Prabhakar R. Changes in canine angulation after dentoalveolar distraction with a rigid maxillary intraoral distractor: a radiographic study. Orthod J Nepal 2013 Feb;3(2):235-241.

15. Alainawi KAY, Hajeer M. The effect of a modified distractor on canine angulation during rapid canine retraction. Proceedings of the 17th Syrian Conference of the Arab Association of Surgeons Oral and Maxillofacial Surgeons; 2014; Damascus, Syria. p. 14. 